\title{
Targeted food supplementation through National Nutrition Program and pregnancy weight gain status in selected upazilas
}

\author{
Karim $\mathrm{MR}^{1}$, Flora $\mathrm{MS}^{1}$, Akhter $^{2}$ \\ ${ }^{I}$ Department of Epidemiology, National Institute of Preventive and Social Medicine (NIPSOM), Dhaka \\ ${ }^{2}$ Army Medical Core, Combined Military Hospital, Dhaka Cantonment, Dhaka
}

\begin{abstract}
A record based operational research was conducted to explore the effect of targeted food supplementation of National Nutritional Program on pregnancy weight-gain. Records of chronic energy deficient mothers who delivered their baby between $1^{\text {st }}$ January and $31^{\text {st }}$ December, 2008 in the study areas were reviewed. The study included 439 samples from Kapasia sub-district, a National Nutritional Program intervention area and 126 samples from Savar subdistrict, as control area. In the National Nutritional Program area 211 (48\%) of the chronic energy deficient mothers were enrolled for supplementation and only $34(8 \%)$ of them completed the full course. Samples of Kapasia and Savar were significantly different in their socio-demographic status. The early-pregnancy average body mass index of supplemented mothers $(16.21 \pm 0.77)$ was significantly different from non supplemented mothers of Kapasia (17.14 \pm .82$)$ and Savar areas (17.03 \pm 1.19$)$. Average pregnancy weight gain in mothers of control area $(6.50 \pm 1.53 \mathrm{~kg})$ were significantly lower than supplemented $(7.94 \pm 1.99 \mathrm{~kg})$ and non-supplemented mothers $(7.82 \pm 2.28 \mathrm{~kg})$ in National Nutrition Program intervention area $(\mathrm{p}<0.001)$. Multivariate analysis showed supplemented mothers were six times [OR with 95\% CI; 6.34 $(2.43,16.52)$ and non-supplemented mothers from same area were eleven times more likely to gain targeted weight than the mothers of control area after adjusting for other variables. Duration of supplementation did not show any influence on pregnancy weight gain. The current study showed significant difference in weight gain between National Nutrition Program area and control area, but no significant difference was noticed between non-supplemented and supplemented mothers within National Nutrition Program area. A large-scale well-designed trial is recommended to explore this effect.
\end{abstract}

\section{Introduction}

Pregnancy is thought to be the most vulnerable stage of woman's life and protecting her health along with her fetus during this period yields a positive impact on the health of future generations. One of the most important factors affecting maternal and fetal health is nutritional adequacy during pregnancy. Maternal poor nutrition and health during pregnancy is of importance for the high prevalence of low birth weight $(<2500 \mathrm{gm})$ and fetal growth retardation. Annually ten million low birthweight babies are born in South-central Asia and in Bangladesh the prevalence of low birth weight is forty percent ${ }^{1-4}$.

In countries where Infant Mortality Rates (IMR) is high, low birthweight (LBW) infants account for the largest share of $\mathrm{IMR}^{1}$. Low birthweight is associated with foetal and neonatal morbidity, inhibited growth and cognitive development and chronic diseases later in life. Poor maternal nutritional status leads to many complications for both mother and baby ${ }^{5-7}$.
The important role of low birth weight and prematurity for perinatal mortality and morbidity in developing countries and its association with under-nutrition and malnutrition in the mothers', had motivated various attempts to improve pregnancy outcome through food supplementation strategy. Several studies showed that daily food supplementation to malnourished pregnant women not only decreased the risk of maternal death and birth of low birthweight infants but also improved children's growth and breast milk adequacy ${ }^{8,9}$.

The anthropometry of the mother and her nutritional intake, pre-pregnancy weight, body mass index (BMI) and gestational weight gain all have strong, positive effects on foetal growth suggesting that energy balance is an important determinant of birth outcomes ${ }^{10,11}$. The World Health Organization (WHO) collaborative study, reported that mothers in the lowest quartile of prepregnancy weight, carried two to three times excess risk of developing intra-uterine growth retardation (IUGR) and low birth weight (LBW) respectively, compared to the upper quartile. 
The Institute of Medicine (IOM) issued its weight gain guidelines for maternal weight gain during pregnancy based on pre-pregnancy body mass index and recommended that women who are underweight before pregnancy should gain more weight during pregnancy ${ }^{12-14}$.

Maternal nutritional status at the beginning of gestation and the rate of fat gain early in pregnancy is the two indicators most strongly associated with birth-weight ${ }^{15,16}$. The Gambian supplementation trial had succeeded in reducing both stillbirth and neonatal death by providing a much higher net increase in energy intake by rural mothers ${ }^{17-19}$. Study in Iran showed, traditional food supplementation enhanced higher maternal weight gain $(\mathrm{p}<0.02)^{20}$.

Low weight gain in pregnancy is associated with increased risk of preterm delivery, particularly if women are underweight or of average weight before pregnancy ${ }^{21}$. But still there is increasing evidence that higher weight gains during pregnancy do not improve infant outcomes and instead may elevate the mothers' long-term risk of chronic disease ${ }^{22,23}$.

Operational research on National Nutrition Program (NNP) food supplementation showed that food supplementation did not lead to enhanced pregnancy weight gain with the exception of severe malnutrition category ${ }^{24}$. The important determinants for the distribution of the effect of supplementation provided by NNP seem to be the mothers' pre-pregnancy weight, her basic dietary intake during this period, the energy and nutrient composition of the supplement, the timing and total duration of supplementation and the replacement level of the supplement ${ }^{25}$.

Recent studies raised queries about the efficiency of the National Nutrition Program in enhancing pregnancy weight gain thus reducing prevalence of low birth weight ${ }^{26}$. The results of this research may provide scopes for further modification and better implementation strategy of the National Nutrition Program.

\section{Materials and Methods}

This post test only non-experimental operational research was aimed to evaluate the effect of targeted food supplementation by NNP. The samples were taken from two different sub-districts served by two different national non-government organizations. Voluntary Association for Rural Development (VARD) was implementing the maternal and child nutritional supportive program following NNP guidelines in Kapasia sub-district and Savar subdistrict was taken as control area where Gonosashthaya Kendra was delivering comprehensive maternal and child health care services.

Records of all chronic energy deficient pregnant mothers who delivered their baby between $1^{\text {st }}$ January and $31^{\text {st }}$ December; 2008 in both study areas were reviewed. Singleton mothers who did not have any chronic disease, delivered at term and were registered within 120 days of last menstrual period were selected as study samples.

Data taken from records included sociodemographic, reproductive, food supplementation and pregnancy weight at different gestational age. Early pregnancy weight measured at registration time was taken as first weight and the last measurement taken before delivery, was considered as end line weight and pregnancy weight gain was computed.

Records revealed that 228 out of 439 chronic energy deficient mothers of NNP area were notsupplemented. So the analyses were performed comparing three categories: Non NNP area $(n=126)$, NNP not supplemented $(n=228)$, NNP supplemented $(\mathrm{n}=211)$.

The NNP supplemented mothers were further subdivided into poor, moderate and good supplementation categories considering total number of supplementation days as stated by Santhia et al: (<120 days), (120-159 days) and ( $\geq 160$ days) for registration month three. In registration month 4 , low, intermediate and high supplementation groups were defined as $<100$ days, 100 - 139 days and $\geq 140$ days, respectively.

Data management and analysis were done with the help of SPSS 16.0 version for windows. The research protocol was approved by the ethical committee of the National Institute of Preventive and Social Medicine (NIPSOM), Dhaka, Bangladesh.

\section{Results}

The socio demographic characteristics of the samples of NNP (supplemented and non supplemented) and control area were compared. Although the mean age of the pregnant mothers in all categories was around 24 years, the distribution was significantly different especially between control and NNP area; NNP area included relatively younger mothers than control area. Illiteracy was more common in Savar area (mothers $21.4 \%$ and fathers 19.8\%) than their Kapasia counterpart. NNP and control area were also different in the occupation of the father. All mothers were housewives. Almost all mothers of NNP area visited for antenatal care $($ ANC) $\geq 4$ times whereas one-third of mothers in control area did 
not. Supplemented mothers from Kapasia area had, on average, lower body mass index (BMI) $(16.21 \pm 0.77)$ than non supplemented mothers in Kapasia (17.14 \pm .82$)$ and those in Savar $(17.03 \pm 1.19)$ area. More than $90 \%$ of supplemented mothers were at or below chronic energy deficiency level II (CED II) [table I]. Severe malnutrition (CED III) mothers were more common in supplemented group whereas CED I were more in non supplemented and control mothers.

Table I: Background characteristics of study samples

\begin{tabular}{|c|c|c|c|c|c|c|c|}
\hline \multirow{3}{*}{$\begin{array}{l}\text { Background } \\
\text { Characteristics }\end{array}$} & \multicolumn{6}{|c|}{ NNP Area } & \multirow[t]{3}{*}{$\mathrm{p}$-value } \\
\hline & \multicolumn{2}{|c|}{$\begin{array}{c}\text { Non NNP area } \\
(n=126)\end{array}$} & \multicolumn{2}{|c|}{$\begin{array}{c}\text { Not } \\
\text { supplemented } \\
(n=228)\end{array}$} & \multicolumn{2}{|c|}{$\begin{array}{l}\text { Supplemented } \\
\qquad(n=211)\end{array}$} & \\
\hline & $\mathrm{n}$ & $(\%)$ & $\mathrm{n}$ & $(\%)$ & $\mathrm{n}$ & $(\%)$ & \\
\hline \multicolumn{8}{|l|}{ Mothers age in yrs } \\
\hline$\leq 19$ & 8 & (6.3) & 29 & $(12.7)$ & 38 & (18.0) & \\
\hline $20-24$ & 54 & $(42.9)$ & 98 & $43.1)$ & 84 & (39.8) & \\
\hline $25-29$ & 50 & $(39.7)$ & 58 & $(25.4)$ & 51 & $(24.2)$ & $0.006^{*}$ \\
\hline $30-34$ & 10 & $(7.9)$ & 24 & $(10.5)$ & 26 & (12.3) & \\
\hline$\geq 35$ & 4 & (3.2) & 19 & $(8.3)$ & 12 & $(5.7)$ & \\
\hline \multicolumn{8}{|l|}{ Mothers education } \\
\hline No education & 27 & $(21.4)$ & 14 & $(6.1)$ & 15 & (7.1) & \\
\hline$<$ Primary & 10 & (7.9) & 48 & $(21.1)$ & 61 & $(28.9)$ & $<0.001^{*}$ \\
\hline $5-9$ years & 78 & $(61.9)$ & 129 & $(56.6)$ & 108 & $(51.2)$ & \\
\hline $\begin{array}{l}\text { SSC and above } \\
\text { Fathers' education }\end{array}$ & 11 & $(8.8)$ & 37 & $(16.2)$ & 27 & (12.8) & \\
\hline No education & 25 & (19.8) & 27 & $(11.8)$ & 30 & $(14.2)$ & \\
\hline$<$ Primary & 14 & (11.1) & 69 & $(25.9)$ & 72 & $(34.1)$ & $<0.001^{*}$ \\
\hline $5-9$ years & 68 & $(54.0)$ & 105 & $(46.1)$ & 80 & (37.9) & \\
\hline SSC and above & 19 & (15.1) & 37 & $(16.2)$ & 29 & (13.7) & \\
\hline \multicolumn{8}{|l|}{ Fathers' occupation } \\
\hline Unemployed & 3 & $(2.4)$ & 7 & $(3.1)$ & 9 & (4.3) & \\
\hline Heavy worker & 46 & (36.5) & 103 & $(45.2)$ & 124 & $(58.8)$ & \\
\hline Skilled labour & 30 & (23.8) & 21 & $(9.2)$ & 17 & (8.1) & $<0.001^{\star}$ \\
\hline Businessman & 25 & (19.8) & 64 & $(28.1)$ & 39 & (18.5) & \\
\hline Serviceman & 22 & (17.5) & 33 & $(14.5)$ & 22 & (10.4) & \\
\hline \multicolumn{8}{|l|}{ ANC category } \\
\hline Less than four visit & 42 & (33.3) & 7 & (3.1) & 5 & (2.4) & \\
\hline More than four visit & 84 & (66.7) & 221 & $(97.5)$ & 206 & (96.9) & $<0.001^{\star}$ \\
\hline BMI (Mean \pm SD) & \multicolumn{2}{|c|}{$17.03 \pm 1.19$} & \multicolumn{2}{|c|}{$17.14 \pm 82$} & \multicolumn{2}{|r|}{$16.21+77$} & $<0.001^{\star \star}$ \\
\hline$\underline{\text { CED categories }}$ & & & & & & & \\
\hline CED I & 78 & (61.9) & 140 & (61.4) & 14 & $(6.6)$ & \\
\hline CED ॥ & 26 & (20.6) & 72 & (31.6) & 132 & $(62.6)$ & $<0.001^{*}$ \\
\hline CED III & 22 & (17.5) & 16 & $(7.0)$ & 65 & (30.8) & \\
\hline
\end{tabular}

Significance shown in the table are for comparison among different supplementation categories

*p values obtained by $\chi^{2}$ test; ** $\mathrm{p}$ value obtained by $\mathrm{F}$ test.

On average, control mothers gained lowest weight $(6.50 \pm 1.53 \mathrm{~kg})$ and NNP supplemented group gained highest weight $(7.94 \pm 1.99 \mathrm{~kg})$. No difference was observed in the weight gain between supplemented and non-supplemented mothers of Kapasia NNP area. [table II]. After adjusting for socio-demographic and early BMI status the relationship persisted [table II]. Similar findings were observed when pregnancy weight gain was categorized as targeted weight gain (9 kg as cut off) and tested [table III]. After adjustment supplemented mothers were six times more likely to gain targeted weight [OR with 95\% CI 6.34 $(2.43,16.52)]$ than mothers of control area whereas non-supplemented mothers of NNP were eleven times more likely to gain targeted weight (OR with $95 \%$ CI 10.62 [4.15, 27.17]). The number of mothers who gained adequate weight were also proportionally higher within good supplemented category [Figure 1].

Only eight percent of all eligible Kapasia pregnant mothers got full course of supplementation. Good supplemented mothers gained, on average higher weight $(8.50 \pm 1.6 \mathrm{~kg})$ although the differences were not statistically significant [Figure 2].

Table II: Pregnancy weight gain according to supplementation status

\begin{tabular}{lrrrrr}
\hline \multicolumn{1}{c}{ Supplement status } & \multicolumn{5}{c}{ Pregnancy weight gain status } \\
& \multicolumn{5}{c}{ Adjusted for other variables } \\
& Mean \pm SD & p & $\beta$ & F change & p \\
\hline Non NNP area* & $6.50 \pm 1.53$ & & & & \\
NNP Non-supplemented & $7.82 \pm 2.28$ & $<0.001$ & .32 & 19.62 & $<0.001$ \\
NNP Supplemented & $7.94 \pm 1.99$ & .26 & & \\
* Reference category. Non NNP area & & & & \\
CI $=$ Confidence Interval & & & &
\end{tabular}

Table III: Weight gain category by supplementation status

\begin{tabular}{|c|c|c|c|c|c|}
\hline \multirow[t]{2}{*}{ Supplement status } & \multicolumn{5}{|c|}{ Pregnancy weight gain category } \\
\hline & $\begin{array}{l}<9 \mathrm{~kg} \\
\mathrm{~N}(\%)\end{array}$ & $\begin{array}{l}>9 \mathrm{~kg} \\
\mathrm{~N}(\%)\end{array}$ & $\mathrm{p}$ & $\begin{array}{c}\text { Crude } \\
\text { OR[95\% Cl] }\end{array}$ & $\begin{array}{c}\text { Adjusted } \\
\text { OR [95\%Cl] }\end{array}$ \\
\hline Non NNP area* & $120(95.2)$ & $6(4.8)$ & & & \\
\hline $\begin{array}{l}\text { NNP Non- } \\
\text { supplemented* }\end{array}$ & $147(64.5)$ & $81(35.5)$ & $<0.001$ & $\begin{array}{c}11.02 \\
(4.65,26.14)\end{array}$ & $\begin{array}{c}10.62 \\
(4.15,27.17)\end{array}$ \\
\hline NNP Supplemented & $136(64.5)$ & $75(35.5)$ & & $\begin{array}{c}11.03 \\
(4.64,26.25)\end{array}$ & $\begin{array}{c}6.34 \\
(2.43,16.52)\end{array}$ \\
\hline
\end{tabular}

* Reference category=Non NNP area

$\mathrm{CI}=$ Confidence Interval
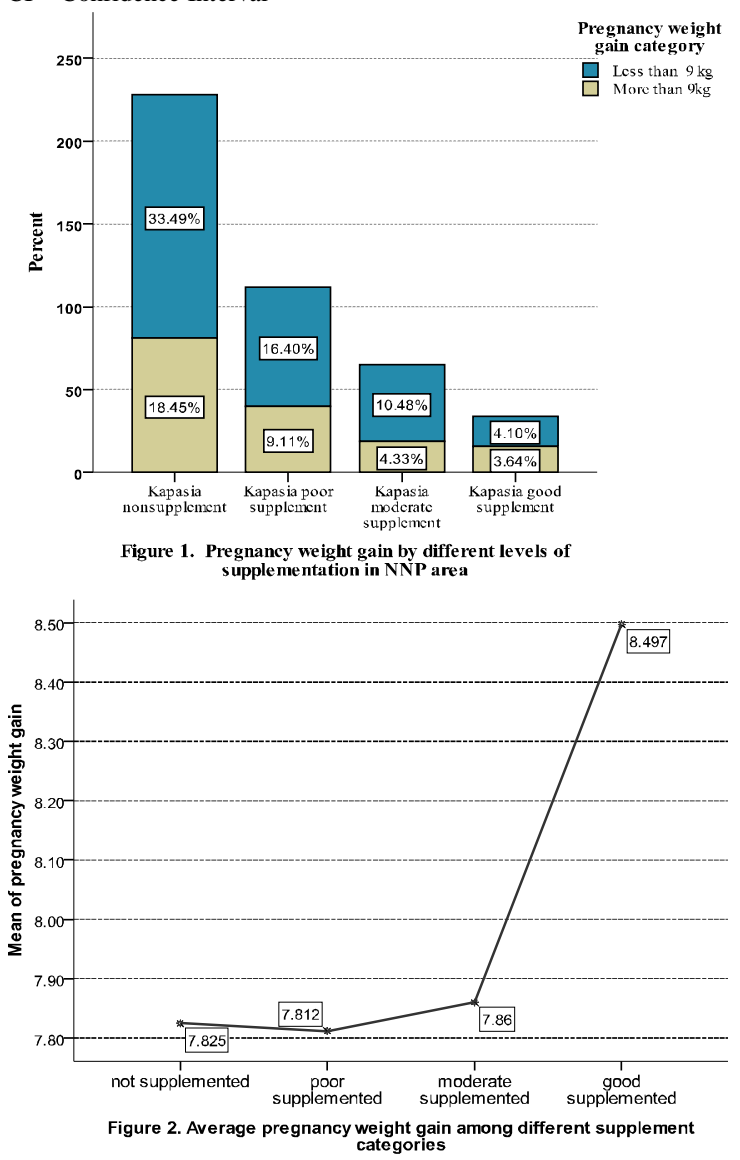


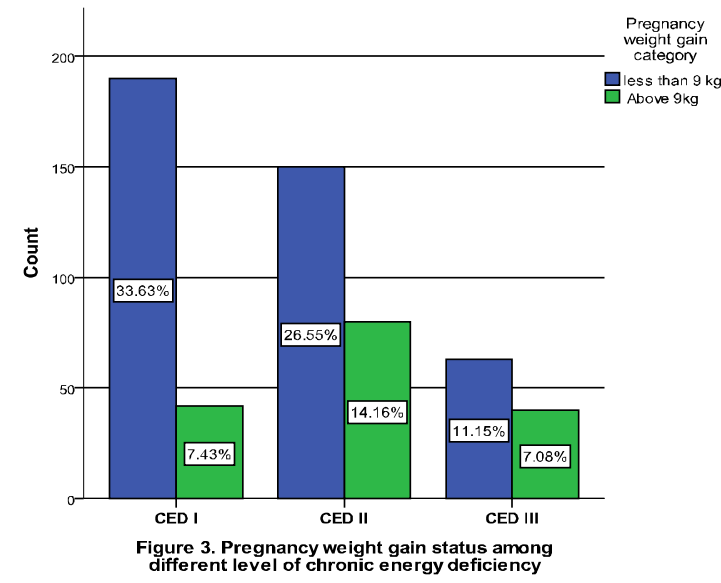

Discussion

This study was performed to assess the effects of nutritional intervention in pregnancy using projectbased data.

Nearly half of the supplemented mothers started late supplementation and only about one in ten women received full supplementation. This result indicated serious deficiencies in the implementation of the NNP in rural areas ${ }^{26,27}$.

In this study weight gain was inversely related with initial weight. Women with CED III gained higher weight, on average during their pregnancy than CED I women and it was consistent with other studies in Bangladesh ${ }^{24,26,28}$ Indonesia $^{29}$, Pakistan ${ }^{30}$ and Taipei ${ }^{31}$. [fig.2 \& fig.3]. The food supplementation in the NNP might be a replacement not a supplement, which was supported by the findings of Bangladesh Integrated Nutrition Program (BINP) operational research that $30 \%$ of the women substituted at least part of their domestic food intake by NNP food supplements ${ }^{32}$. The average monthly weight gain in the present study was considerably lower, averaging only $0.92 \mathrm{~kg} /$ month in the second and third trimesters although a WHO collaborative study showed that weight gain of 1.5 $\mathrm{kg} /$ month during the last two trimesters was consistent with good pregnancy outcomes ${ }^{33}$.

The results of the present study also showed that severely malnourished women gained more weight in pregnancy. Several researchers proposed that when seriously malnourished women were supplemented they could not 'afford' to direct the energy to the fetus and therefore such supplementation improved maternal weight gain more than birth weight ${ }^{34,35}$. Apart from frustrating coverage of the supplementation program this finding directed our view to the composition of the supplementation regimen provided by the NNP, that contain lesser amount of protein [all the protein derive from vegetable source] than any other regimen trialed so far ${ }^{19,20,36}$.
The importance of taking data from two areas was not established in a way that it was planned for. The differences of pregnancy weight gain among categories were partly seemed to be affected by selection and measurement bias. The formats as well as the workers involved with the data collection procedure of two organizations were dissimilar (in terms of training, experience and education). The logistics were also different (some used digital machines and others used calibrated scale). Monitoring and data quality checking were also not uniform for different organization. As it was a record based study, potential limitation is reliance on reported anthropometric measurement, height of the mothers, and weight of the mothers. We relied on the records for the likelihood that any biases which might continue to exist (e.g. from faulty weighing scales, recording errors, or intentional misrepresentation) would equally affect the data on the supplemented and nonsupplemented women.

Conclusion: The program coverage was about half in terms of eligibility but in terms of adequate supplementation it was only eight percent. The study found that there were significant differences in pregnancy weight gain between NNP and non NNP areas but no such difference were observed between supplemented and non-supplemented mothers of NNP area. A large-scale well-designed trial is recommended to explore the effect of targeted food supplementation.

\section{References}

1. ACC/SCN Symposium .Women and Nutrition. Policy Discussion paper 1990; 6: 124-125.

2. Subcommittee on nutritional status and weight gain during pregnancy, Subcommittee on dietary intake, nutrient supplements during pregnancy. Nutrition during pregnancy: Executive Summary. Nutrition Today 1990; 13-22.

3. Low Birthweight; Country, regional and global estimates. United Nations Children's Fund and World Health Organization. UNICEF, New York; 2004.

4. FAO Corporate Document Repository, Food-based nutrition strategies in Bangladesh, FAO Regional Office for Asia and the Pacific; 2007.

5. Barker. DJP (ed.), Fetal and infant origins of disease, BMJ Books, London, 1st Edition; 1992.

6. Vause T, Martz P, Richard F, et al. Nutrition for healthy pregnancyoutcomes. Appl Physiol Nutr Metab 2006; 31(1): 12-20

7. Winkvist A, Stenlund H, Hakimi M, et al. Weight gain patterns from pre-pregnancy until delivery among women in Central Java, Indonesia. Am $\mathrm{J}$ lin Nutr 2002;75(6):1072-7

8. Subcommittee on nutritional status and weight gain during pregnancy, Food and Nutrition Board, US Institute of Medicine/National Academy of Sciences. 
Nutrition during pregnancy. Washington (DC): National Academy Press; 1990.

9. Tontisirin, K, Booranasubkajorn, U. and Hongnsumarn. A. et al. Formulation and evaluation of supplementary foods for Thai pregnant women. Am. J. Clin. Nutr 1986; 43: 931-939.

10. Subcommittee on nutritional status and weight gain during pregnancy, Food and Nutrition Board, US Institute of Medicine/National Academy of Sciences. Nutrition during pregnancy. Washington (DC): National Academy Press; 1990.

11. World Health Organisation. Maternal anthropometry and pregnancy outcomes: a WHO collaborative study. Bull World Health Organ. 1995; 73 (Suppl): 1-98.

12. Abrams B, Altman SL, Pickett KE. Pregnancy weight gain: still controversial. Am J Clin Nutr 2000; 71(5): 1233s- $41 \mathrm{~s}$.

13. Burrowes JD. Nutrition for a lifetime: Maternal Nutrition. Nutrition today 2006; 41(6): 267-73.

14. Stotland NE, Hopkins LM, Caughey AB. Gestational weight gain, macrosomia, and risk of cesarean birth in nondiabetic nulliparas. Am College Obstetr Gynecol 2004;104(4):671-7.

15. Villar J, Cogswell M, Kestler E, Castillo P, Menendez, R \& Repke JT. Effect of Fat and Fat-Free Mass Deposition during Pregnancy on Birth Weight. American Journal of Obstetrics and Gynecology 1992; 167(5):1344-1352.

16. Panahandeh Z. Gestational Weight Gain and Fetal BirthWeight in Rural Regions of Rasht/Iran. Iran J Pediatr 2009; 19 (1): 18-24.

17. Rush D. Maternal nutrition and perinatal survival. J Health Popul Nutr. 2001; 19: S217-64.

18. Ceesay SM, Prentice AM, Cole TJ, Foord F, Weaver LT, Poskitt EME et al. Effects on birth weight and perinatal mortality of maternal dietary supplements in rural Gambia: 5 year randomised controlled trial. $\mathrm{Br}$ Med J 1997; 315:786-90.

19. Villar J, Cogswell M, Kestler E, Castillo P, Menendez R \& Repke J.T. Effect of Fat and Fat-Free Mass Deposition during Pregnancy on Birth Weight. American Journal of Obstetrics and Gynecology 1992; 167(5):1344-1352.

20. Kaseb F, Kimiagar M, Ghafarpoor M, Valaii N. Effect of traditional food supplementation during pregnancy on maternal weight gain and birthweight. Int J Vitam Nutr Res 2002; 72(6):389-93.

21. Schieve LA, Mary CE, Scanlon KS, Perry G, Ferre C, Blackmore-Prince C, YU SM, AND Rosenberg D. For the NMIHS Collaborative Working Group, Pre pregnancy Body Mass Index and Pregnancy Weight Gain. Associations with preterm delivery. American Journal of Obstetrics and Gynecology 2000; 96(2): 194-200.

22. Caulfield LE, Stoltzfus RJ, Witter FR. Implications of the Institute of Medicine weight gain recommendations for preventing adverse pregnancy outcomes in black and white women. Am J Public Health 1998; 88: $1168-74$.
23. Stevens-Simon C, McAnarney ER. Adolescent pregnancy Gestational weight gain and maternal and infant outcomes. Am J Dis Child 1992; 146: 1359-64.

24. Ortolano SE, Mahmud Z, Kabir AFMI, Levinson FJ. Effect of Targeted Food Supplementation and Services in the Bangladesh Integrated Nutrition Project on Women and Their Pregnancy Outcomes. J Health Popul Nutr 2003; 21:83-9.

25. Rich-Edwards J, Krieger N, Majzoub J, Zierler S, Lieberman E, Gilman M. Maternal experiences of racism and violence as predictors of preterm birth: rationale and study design. Paediatr Perinat Epidemiol 2001; 15(Suppl): 124-35.

26. Nahar S, Nicholas Mascie Taylor CG and Begum HA .Impact of targeted food supplementation on pregnancy weight gain and birth weight in rural Bangladesh: an assessment of the Bangladesh Integrated Nutrition Program (BINP), Public health nutrition 2009; 12(8): 1205-1212.

27. The World Bank: Maintaining Momentum to 2015? An Impact Evaluation of Interventions to Improve Maternal and Child Health and Nutrition in Bangladesh. Washington, DC: World Bank; 2005.

28. Nicholas Mascie-Taylor CG. Rahman M, Karim E, Moji K, Minamoto K. The relationship between maternal anthropometry and childhood malnutrition in rural Bangladesh. American Journal of Physical Anthropology 2004; 45: 109-118.

29. Kusin JA \& Kardjati S. Maternal and Child Nutrition in Madura, Indonesia. Amsterdam: Royal Tropical Institute; 1994.

30. Winkvist A, Habicht J-P \& Rasmussen K. Linking maternal and infant benefits of a nutritional supplement during pregnancy and lactation. American J Clin Nutr 1998; 68: 656-661.

31. SiegaRiz A, Adair L \& Hobel C. Maternal undernutrition and inadequate rate of weight gain during third trimester of pregnancy increases the risk of preterm delivery. J Nutr 1996; 126: 146-153.

32. Abdullah M, Karim R \& Samad QA. Is the supplement a substitute or true supplementation to the usual diet?. In Results from the BINP Operations Research: International Centre for Diarrhoeal Disease Research; Dhaka Bangladesh 2000; 2: p. 9.

33. World Health Organization. Maternal anthropometry and pregnancy outcome: a collaborative project. Bull World Health Organ 1995; 73:Suppl:1-98.

34. Pelto G, Dickin $\mathrm{K} \&$ Engle PA. Critical Link: Interventions for Physical Growth and Psychological Development: A Review. WHO/CHS/CAH/99.3. Geneva: Department of Child and Adolescent Health and Development, WHO. 1999.

35. Olson R. Developing Indicators that Predict Benefit from Prenatal Energy Supplementation. New York: Cornell University Press, Ithaka; 1994.

36. Metcoff J, Costiloe P, Crosby WM, Dutta S, Sandstead HH, Milne D, Bodwell CE, Majors SH. Effect of food supplementation (WIG) during pregnancy on birth weight. Am J Clin Nuir 1985; 41: 933-947. 